INTERNATIONAL DESIGN CONFERENCE - DESIGN 2018

https://doi.org/10.21278/idc.2018.0274

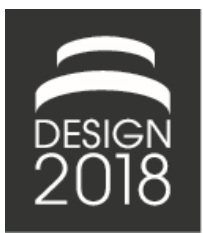

\title{
DEVELOPMENT OF A RAPID CO-PROTOTYPING ENVIRONMENT FOR INDUSTRIAL SERVICES
}

\author{
M. E. Lammi, P. T. Helo, J. H. Arrasvuori, P. L. Yli-Viitala, J. Pekkala and S. L. Peltonen
}

\begin{abstract}
Service-oriented industrial companies need to manage the complexity of developing new services (NSD) besides products. Prototyping offers a way to increase the success of NSD. There are service prototyping environments, but they fall short in effectiveness. CoProtolab concept was developed for effective, comprehensive, immersive and collaborative prototyping of industrial services in a physical and virtual environments. The research follows an axiomatic design theory and results in a theoretical model for studying and developing virtual, physical and social service prototyping environments.
\end{abstract}

Keywords: product-service systems (PSS), rapid prototyping, virtual prototyping, design science

\section{Introduction}

Service-oriented industrial companies need to manage the complexity of developing new services (NSD) besides products (Gebauer et al., 2005). In addition to the complexity, the abstract and often secondary nature of services in companies, challenges the implementation of NSD. Prototyping is highlighted as a way to increase the success of NSD (Kindström and Kowalkowski, 2009) and supporting rapid, customer-centric service innovation (Ostrom et al., 2015).

Prototyping is defined as "the use of prototypes to explore, evaluate and communicate design". (Blomkvist, 2014) Prototyping refers to the activity of studying and developing solutions of the future, while prototypes are the representations of design ideas. Representations can be 'definite' - pre-prepared material such as sketches and videos, or 'ongoing' - participatory activities such as role-plays or desktop walkthroughs (Blomkvist, 2014). However, using definite and ongoing prototypes simultaneously could support quick and collaborative prototyping. Therefore, there is a need for new ways of advancing prototyping activities.

This study aims at defining key elements of physical and virtual environments for supporting industrial service prototyping along NSD processes. The paper depicts the concept development of prototyping environment and proposes a theoretical model for supporting industrial service prototyping. The study follows design science research approach (DSR) (Gregor and Hevner, 2013), which is suitable for iterative processes. The principles of axiomatic design (Suh, 2001) were used for systematizing the multidisciplinary concept development.

Initially, axiomatic design was created for product development, but it has been applied for product service systems as well (Kimita et al., 2009). The axiomatic design aims to capture the customer needs, translate them into functional requirements, which are fulfilled by design parameters, and finally become operational at a process level (Suh, 1998). These four domains need to be coupled through continuous mappings between domains, "what we want to achieve" and "how we want to achieve it". In this research, customer needs are described through multidisciplinary background research and 
benchmarking of service prototyping environments. Functional requirements act as design drivers for concept development. Design parameters present the elements of the prototyping environment and process variables describe the use processes of the physical and virtual environments.

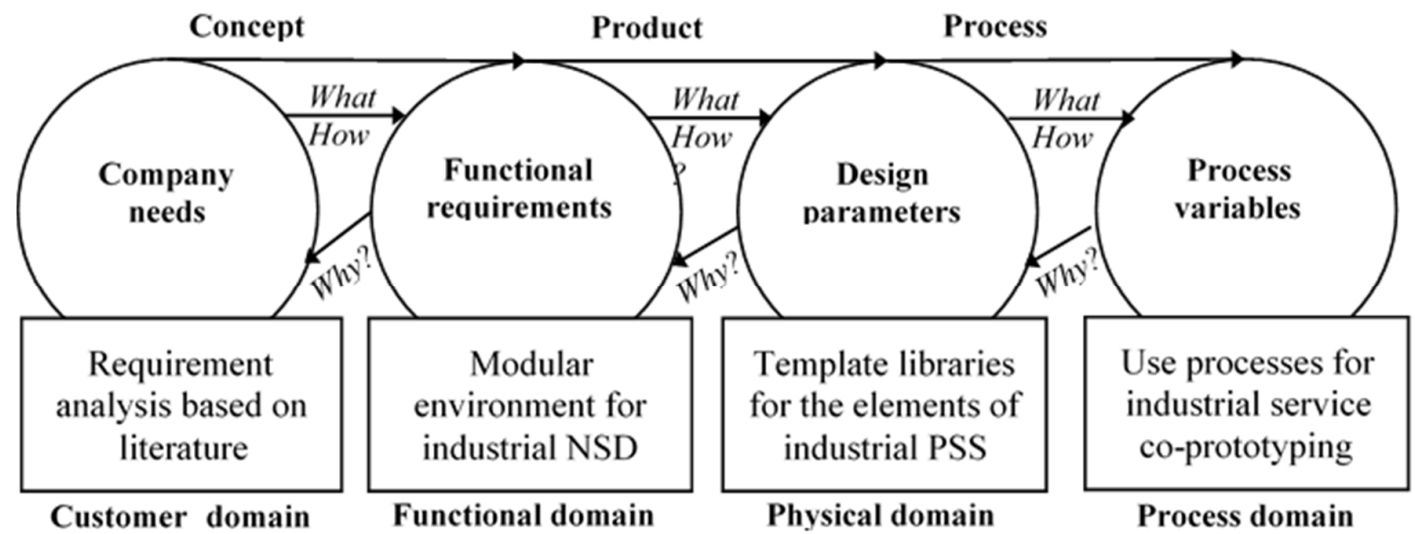

Figure 1. Iterative development of CoProtolab in an accelerated axiomatic loop

This research is part of Co-Protolab project funded by EU - ERDF program, which aims at developing and testing a research, innovation and demonstration environment for industrial service development. The concept development grounded on Isee toolkit (Lammi, 2017), which visualises emotional and functional service experiences of industrial service processes. The toolkit was developed further in a multidisciplinary research team of design, industrial management, marketing and ICT.

This paper presents the development of a concept for physical and virtual environment, which supports quick, collaborative service prototyping in an industrial setting. The study results in a theoretical model for rapid prototyping of industrial services. Researchers and service developers can use the model in creating virtual, physical and social environments for industrial service prototyping. The multidisciplinary approach of the paper opens new research topics in different disciplines as well as possibilities for researchers to test, evaluate and develop the theoretical model.

\section{Concept development for industrial service prototyping environment}

This chapter describes the application of Axiomatic design (AD) methodology to the concept development process. The concept development is a hierarchical decomposition process that starts by identifying the key industrial service prototyping needs and then translating these needs into functional requirements (FRs). FRs are the highest level of decomposition in AD. Thirdly, these FRs are the considered as drivers for concept design and they are decomposed into design parameters (DPs) for spatial and virtual elements. The last phase of concept development is to present the process variables (PVs) for using the environment.

\subsection{Needs of companies for industrial service prototyping}

The development of industrial services is discussed among marketing, management, design and engineering. customer- and service-dominant business logics (Heinonen et al., 2010; Vargo and Lusch, 2011) and integrating customers to development (Gustafsson et al., 2012). Service design describes useroriented, collaborative and visual service development (Wetter-Edman et al., 2014; Wallin et al., 2016) and industrial management describes industrial service processes. The combination of different disciplines create a holistic background for the concept development and the theoretical model.

In this study, the multidisciplinary literature of industrial services and service development describe the needs for industrial service prototyping. This study discusses product-service systems as an object of development, and describes the models and challenges of developing industrial services. The significant role of customers in the industrial service development is depicted through service design methods. 


\subsubsection{Industrial service development}

New service development in industrial companies is driven by servitization (Baines et al., 2009). Companies transfer from offering purely products toward services and product-service systems (PSS) incorporating tangible and intangible offerings in order to create customer satisfaction (Haase et al., 2017). Servitization aims at a high-level of customer-centric and networked practices, which end up in co-creating total solutions with customers and suppliers (Baines et al., 2009). Technology is an enabling factor in servitization, which typically means renewal of service offering, value proposition, service delivery and ultimately business models (Helo et al. 2017). Service-oriented industrial companies need to manage the complexity of developing new services (NSD) in addition to products (NPD) (Gebauer et al., 2005). Companies have difficulties in strategic framing, scheduling and integration of business functions of service development (Kindström and Kowalkowski, 2009).

Extant research proposes several models for designing PSS. Isaksson et al. (2011) presented a framework for developing PSS that covers the identification of needs and solutions as well as implementation, support and closure of a solution. Morelli (2002) focuses in concept design of PSS solutions, which specify the detailed development. Service design propose methods for studying users, their service journeys and touchpoints, and creates solutions for better experiences (Mager, 2009; Stickdorn et al., 2010). Industrial service design need to handle the complexity of development through intra and inter-organisational partnering, change programs and co-creation methods, which require considerable preparation (Miettinen, 2017). Service design can support servitization in understanding and supporting service experiences of both customers and service providers (Lammi, 2017).

\subsubsection{Customer integration in designing product-service systems}

Development of successful offerings requires in-depth understanding of the customers, their situation, needs and wants, which calls for active interaction with the customers during the development (Lagrosen, 2005). When customers is emphasised new landscapes for value formation can arise (Heinonen et al., 2013) opening new business or innovation opportunities (Heinonen et al., 2010). When companies aim to discover the potential, unrealized value of a new service, they need to learn and support customer processes in their context (Grönroos, 2008; Heinonen et al., 2010). On the other hand, service providers are tied to their capabilities, resources, business models and strategies. The challenge for service providers is to step outside their own context to the world of a customer (Heinonen and Strandvik, 2015). Flint (2002) suggests that taking part in customers' activities while retaining the researcher or intelligence generator role (and not a selling role), deep insights can emerge.

From the customer's perspective, offerings are not only consumed or used, but potentially integrated into the customer's on-going experience and activity structures beyond the service situations or service process. This means that service providers need to take into account, not only the customer's core activities and experiences related to service usage, but also a larger picture of value creation (Heinonen et al., 2010). In service context, the value is not embedded in unites of output and exchange rather than realized through experiences when the customer activates and uses the service provider's offering and resources (Voima et al., 2010). A central question is how companies can support customers' on-going activity and experience structures (Heinonen et al., 2010).

\subsubsection{Environments for service prototyping}

Prototyping is proposed as a key function in NSD for ensuring the fulfilment of value proposition of a service (Kindström and Kowalkowski, 2009). Prototyping has been used for conceptual studies of services, creating empathy for users, communicating with stakeholders, designing service logic as well as testing the service concept (Bae and Leem, 2014). Prototyping supports communication, saves resources by enabling the identification of problems in early stages (McCurdy et al., 2006), and manages uncertainty of new ideas (Blomkvist, 2014). In addition, prototyping creates confidences on the progress of development, and enables handling problems as learning opportunities. This ensures the functionality and feasibility of a solution as an outcome of prototyping activity (Parker and Heapy, 2006; Jégou and Manzini, 2008).

Several environments have been developed for supporting service prototyping, for example ServLab (Fraunhofer IAO Laboratory, Germany), S-Scape (KITECH, South Korea) SINCO (University of 
Lapland, Finland) (Bae and Leem, 2014). The service prototyping environments use digital representations, such as 3D models, videos and photos, which can be shared, evaluated and used for idea generation. The testbeds dedicate to service-interaction design in order to support an internal management process through simulations, and apply methods from the fields of service engineering, service design, and service marketing (Miettinen and Kuure 2013; Bae and Leem 2014). In addition, and SFB / Transregio 29 (Rurh-Universität Bochum, Germany) has developed an industrial PSS development process (Nguyen et al., 2013), and operationalised process included also prototyping phase (Nguyen et al., 2014) .

Fraunhofer IAO's "ServLab" enables virtual prototyping, visualizing and testing new service concepts. It is a platform of techniques for collecting requirements for new services, creation of service concepts, simulation of servicescapes and interaction, as well as training of customer-contact staff (Meiren and Burger, 2010; Gray et al., 2014). SINCO, Service innovation corner is a University of Lapland's prototyping laboratory for experiencing and act out digital service journeys supported by physical mockup elements and separate touchpoint toolkit (Miettinen et al., 2012). SINCO creates fairly low-cost service prototypes, which require pre-production phase. In addition, simultaneous controlling and exploration of simulations requires development (Miettinen et al., 2012). S-Scape is a test bed for service prototypes, which uses virtual reality (VR) in prototyping (Oh et al., 2013). Bae and Leem (2014) pointed out that VR-based service prototypes are expensive and time-consuming. Therefore, the use of immersive VR effectively in service prototyping need further research.

\subsection{Functional requirements for rapid prototyping environment of industrial services}

The need analysis points out functional requirements (FRs) that explain critical issues and potential solution frameworks for successful NSD. The FRs explain the challenges related to the development of industrial services as well as potential solution frameworks. They are the highest-level FRs and can be decomposed into lower level FRs by using zigzagging process. Next, we describe four functional requirements for rapid prototyping environments of industrial services based on literature: Environments need to support comprehensive and effective, collaborative and immersive prototyping.

\subsubsection{Comprehensive prototyping (FR1)}

In industrial context, offerings often consist of PSS (Morelli, 2002), which combines tangible, intangible and temporal elements (Kindström and Kowalkowski, 2009). Holistic and integrative approaches are suggested for managing an increasing complexity (Thackara, 2005; Morelli, 2007; Charnley et al., 2011). PSS design approach contribute to the interpretation of emerging cultural and social patterns, and translates them into a consistent and visible set of requirements for future PSS (Morelli, 2002). In practice, designers work on possible PSS scenarios by sequencing actions, exploring the roles of actors and the organizational structure of a system. In addition, they use design tools to represent a system in all its components (Morelli, 2006).

Service design produces service concepts as the prerequisites for service, which describes the value, service system and service process (Edvardsson and Olsson, 1996). Clark et al. (2000) define service concept as a "picture or statement that encapsulates the nature of the service business and captures the value, form and function, experience, and outcomes of the service." The service concept concretizes "the how" and the "what of service" and helps mediate between customer needs and an organisation's strategic intent (Goldstein et al., 2002). The service concept guides the following service development work of a service system and a service process (Edvardsson and Olsson, 1996). Therefore, service concepts play an important role in creating comprehensive understanding of the developed service.

\subsubsection{Collaborative prototyping (FR2)}

Industrial services are characterised by high interaction and collaboration with customers and by a networked, intra-organizational activities. Because of the nature industrial services, it is often difficult to establish internal consensus regarding new service development (Kindström and Kowalkowski, 2009). Collaboration in industrial service design integrates multiple levels of staff in the organisations of customers and service providers (Miettinen, 2017). The broad base of participants increases understanding of services, creates commitment and opens innovation opportunities (Kindström and 
Kowalkowski, 2009). Prahalad and Ramaswamy (2000) encourage companies to engage their customers in an active, explicit and ongoing development, which is a dialogue of equals (Prahalad and Ramaswamy, 2000).

Service Blueprinting is widely accepted technique for service innovation, improvements, and experience design (Bitner et al., 2008) that specifies customer's and service provider's processes (Shostack, 1982). Blueprinting divides service process into Customer actions, Onstage and Backstage actions, and Support processes. The line of interaction separates the actions of customers and contact employees and the line of visibility the onstage and backstage actions (Bitner et al., 2008). Blueprinting has been developed further in order to consider emotions and different stakeholders' perspectives in service design (Segelström, 2013). New ideas can be generated and shared through collaborative methods, for example walkthroughs or role-plays (Miettinen and Kuure, 2013; Blomkvist, 2014) or design games (Vaajakallio and Mattelmäki, 2014). An ISEE toolkit focuses on industrial service journeys connecting emotional and functional experiences to templates of service moments, which describes users, use situations, activities, interactions and information flows (Lammi, 2017). The methods still need better integration of generating, representing and testing ideas in collaborative development.

\subsubsection{Effective prototyping (FR3)}

Industrial NSD process consists of market sensing, development, sales, and delivery phases (Kindström and Kowalkowski, 2009). However, existing design methodologies for product-service systems focus on the integration of products and services in planning and design phases. The methodologies lack the drivers for development, clear role definitions of stakeholders, influences of business models. Furthermore, clear and flexible processes for co-creation, design and feedback, as well as detailed and qualitative presentations of PSS require development (Vasantha et al., 2012). Therefore, there is need for effective design methodologies for developing complex PSS.

An important, but often ignored part of the NSD is Intellectual Property Management for protecting a new service from competitors. There is a broad variety of methods available for protecting different aspects of a service (Arrasvuori et al., 2015). present a categorization of altogether 31 protection methods that are divided into three groups: Intellectual Property Rights based on national and international legislation (e.g. copyright, patenting, trademark, service mark), contracts based on contract law (e.g. agreements on ownership, trade secrets) and so-called informal protection methods (e.g. secrecy, publishing, productized service packages). In order to support commercialization of service prototype, intellectual property management need to be integrated to prototyping processes.

\subsubsection{Immersive prototyping (FR4)}

Blomkvist (2014) discusses about two different approaches of service prototyping; explorative and evaluative. Evaluative prototyping aims at describing, refining and testing the design on later stages of a design process. The explorative approach uses prototypes as learning tools for communicating solution in order to create an experiential and sensory connection with ideas (Coughlan et al., 2007). Service prototyping can take place in servicescapes, multi-sensory service with layouts and functions, symbols and artefacts, in which service users act and interact with a service (Bitner, 1992). Interaction rises service experiences (emotions, learnings, intentions and feelings), which are affected by expectations and previous experiences (de Vasconcelos et al., 2015). Because of the critical role of multisensory interaction and experiences in service development, immersive and experiential prototyping need attention.

Scenarios are used for describing complex problems in experiential way, yet they have challenges in dynamic settings. 3D simulated user scenarios enable the exploration of complex system solutions with details both at individual and collective levels (Hjelseth et al., 2015). VR has taken simulations even further and can facilitate collaborative design inside 3D world (Bruno and Muzzupappa, 2010). Virtual environments have proved to be feasible alternative to real life settings for example in design (Kuliga et al., 2015) and usability evaluation (Bruno and Muzzupappa, 2010). However, building a 3D scenario for specific design project requires strong IT competences and time resources, (Hjelseth et al., 2015) which calls for more effective solutions to use virtual reality and 3D simulations in industrial service design. 


\subsection{Design parameters of industrial service co-prototyping environment}

The FRs for the industrial services prototyping environment guide the development of DPs. The comprehensive approach (FR1) calls for NSD approach from goal setting to the protection of services. The collaborative activity (FR2) highlights the integration of both customers and service providers. Effective prototyping (FR3) include both cost-effectiveness and an ability to achieve the goals of NSD. It is solved through a modular structure, which is based on the libraries of templates. Immersive prototyping (FR4) focus on a virtual environment, in which the whole service process can be simulated and experienced in actual size. Next we describe the CoProtolab concept the DPs.

The virtual environment includes front and back-stages of both customers and service providers following the blueprinting methodology. Service moments are illustrated as 3D cubes in order to create a suitable level of generalisation of a service situation. Back stages and support processes are described as figures and texts in order to focus the development on service interactions. The service moments are connected with a timeline creating a service journey. A range of service elements is prepared as templates, which are collected into the libraries: Environment, Persona, Machine, Information, Experience and Driver. In addition, Expectations, Content of information and detailed description about service moment is described in textual format, which are placed in virtual world. The elements are coded with costs, which enable evaluation of total costs of the service.

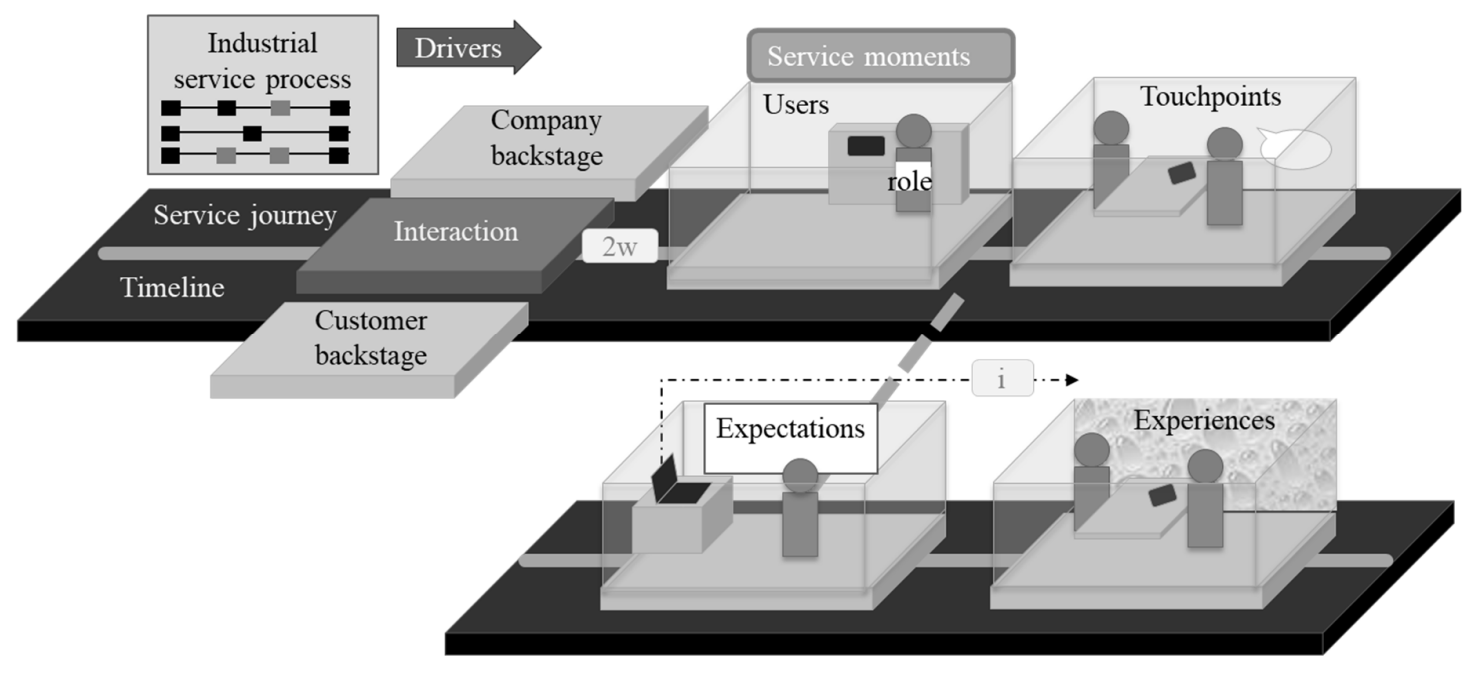

Figure 2. The concept of CoProtolab virtual environment

A service moment contains a service environment, users, and devices in actual size 3D models. (See Figure 2) Service users are described as 3D personas (Pruitt and Adlin, 2010) and their role or name is written on the chest. Their expectations and experiences are written on the whiteboard on the wall. Emotional experiences are illustrated as metaphorical photos (Lammi, 2017) on one wall. There are templates for most typical machines and devices, and communication tools, and the interaction between devices and people are animated actions and information flows. The Driver library is build based on key performance indicators, such as cost, quality, dependability and environmental impact, and the value formation related to service level, pricing, benefits and experiences (Helo et al., 2017).

The physical environment supports prototyping in virtual environment. A technical area is beside a virtual prototyping area. A Collaboration Table with screens presents a service journey and moments with service elements as photos and texts. Prototyping can be focused into single interfaces such as mobile interface, machine display or interaction between users, which can be edited.

Protection library contains different methods for protecting aspects of a new service. Costs and time frames for obtaining protection are associated with the different methods. Different commercialization paths for a service prototype are associated with the different protection methods; for instance, a patent or a trademark can be sold or out-licensed. Informal methods are useful for managing the "noncommercial' components of a service in a smart way for instance publishing a component (e.g. in a white paper) may increase the value of the brand associated with the service. 


\subsection{Process variables for using virtual and physical elements in prototyping}

In AD methodology, the PVs presents a specific process solution and its steps. In this particular study, the process of using the modular elements of the physical and virtual environments during the prototyping flows in an iterative manner. Participants explore a service journey, edit service moments and elements, experience touchpoints and evaluate a prototype. Participants are enlightened to the aims of NSD, future service solutions and protection methods. The environment enables rapid transitions between different prototyping activities and quick alteration of service elements in immersive environment.

The use processes of prototyping environment include initializing and iterating, insuring and informing activities of prototyping. The initialization of a prototype takes place in physical environment around a Collaboration table and iterative prototyping in virtual environment. Insuring a prototype takes place in physical environment and informing about a prototype mainly in virtual environment. Because of the libraries of templates, the process can be carried out in hours rather than weeks. The preliminary process of using the CoProtolab environment is described in Figure 3.

\begin{tabular}{|l|l|}
\hline $\begin{array}{l}\text { Initialize prototyping on } \\
\text { collaboration table }\end{array}$ & $\begin{array}{l}\text { Choose industrial process or concept }>\text { Choose drivers for prototyping }>\text { Edit } \\
\text { service moments, users, environments, devices }>\text { Express expectations }\end{array}$ \\
\hline $\begin{array}{l}\text { Explore, evaluate \& } \\
\text { edit in VR }\end{array}$ \\
\hline $\begin{array}{l}\text { Insure a prototype on } \\
\text { collaboration table }\end{array}$ \\
\begin{tabular}{|l|l|} 
Evaluate \& edit on \\
collaboration table service moments $>$ Evaluate them against \\
form and content of interaction
\end{tabular} \\
\hline $\begin{array}{l}\text { Experience \& edit } \\
\text { in VR }\end{array}$ \\
in VR
\end{tabular}

Figure 3. Use processes of CoProtolab

The spatial concept for facilitating industrial service prototyping covers three views on a prototype. The Experience view supports iterative development in which quick editing and exploration of service journeys connect to collaborative experience of a prototype in a virtual environment. The Process view enlightens the development team, when they establish and carry out a NSD process. Holistic and detailed representations of a service prototype can be modified with quick and collaborative development tools. The Interface view focuses the prototyping into one touchpoint (interaction point) such as the interfaces of devices, mobile applications of web services. The Process and Interface views take place on the Collaboration table in the physical environment.

\subsubsection{Initializing a prototype}

The initialization phase of prototyping aims at creating joint understanding about the current and target states of NSD among the team members. Prototyping can start from an existing service process, service concept, idea or strategic goal for example saving costs. The development team gathers around the Collaboration table, and selects a Service Journey template from the library or constructs a journey from Service Moment templates. Additional elements for example devices, information flows, users, expectations, can be changed and added from libraries of templates in order to meet desired situation. The goal for development is clarified by choosing a template from Driver library or by defining the aim in textual form. A process facilitator supports the teamwork with his topic and process expertise. 
Based on NSD case, a prototyping team is defined, and internal and external users and stakeholders with experience or interests are invited to prototyping sessions. Firstly, the users with the experience or interests of a whole process are integrated. Secondly, the users related to the specific service moments participate to the prototyping. A clear agreement between all participants is made on the ownership status of any Intellectual Property created together. The Protection library offers templates for such contracts. Also, Non-disclosure Agreements are necessary if some information sensitive for a business is used as an input in the prototyping. As a result of initialization phase, the participants, the object and the goals of prototyping are defined.

\subsubsection{Iterating with a prototyping}

The next phase of prototyping takes place in the virtual environment, where participants experience and explore the service journey and compare it to the design drivers. After use instructions, the participants explore a service prototype by walking in and between service moments. They can experience a service moments and express their emotions by choosing a suitable Emotion wallpaper. The participants describe the meanings of the photo as well as other experiences, such as learning outcomes and intentions, which appear as texts on a whiteboard simultaneously.

The participants can edit elements of a prototype by removing and adding templates from virtual libraries. The drivers are used for guiding the changes made to the prototype. Several persons can participate to iterative prototyping in virtual world and the others can observe prototyping on the large screens. Physical whiteboards can be used for taking notes about new ideas, which can be tested in virtual world. A technical facilitator supports usage of the virtual world, while process facilitator supports the teamwork. A prototype is saved after one round of exploring, editing and evaluating a journey and several prototypes can be iterated during the session.

\subsubsection{Insuring a prototype}

CoProtoLab's NSD process consists of a specific module for protecting a new service in its prototype stage. This module has five consecutive steps of actions. The starting point for protection and commercialization is the service prototype as currently documented, specified and/or implemented. The prototype is divided into its components. The components are grouped based on commercialization path and suitability for protection (as enabled by protection methods). CoProtoLab's protection method library is referenced for deciding protection of each prototype component. Legal team of the firm may be consulted.

A plan for protecting and commercializing selected components is drawn. When planning commercialization, the time acquired for desired protection to a component needs to be considered. The plan for protecting and commercializing selected components of the prototype is executed. A number of options are available within two primary paths: a. Commercialization path, e.g. commercializing component(s) in an existing service, commercializing component(s) in a new service or sell component(s) or out-license component(s). The Management path for the 'non-commercial' components uses protection methods such as publishing or keeping in secret.

\subsubsection{Informing about a prototype}

A final prototype PSS as a materialisation of business benefits require discussion and evaluation of companies' capabilities with decision-makers (Rodrigues et al., 2017) in order to allocate resources for detailed service development. In addition, CoProtolab can be used for guiding and inspiring backstage developers by exploring and evaluating a prototype. The participants write notes for backstage development in order to inform technical development team.

A prototype can be used for educating future service staff to act upon a new service model. Target service experiences can be shared and linked to service actions and interactions. Service sales personnel can use the prototypes in presenting their services to potential customers. This may prevent problems in a service delivery phase related to, for example uneven quality, poor delivery processes as well as internal miscommunication, between sales and the service delivery functions (Kindström and Kowalkowski, 2009). 


\section{Discussion}

The paper presented a design science research (Gregor and Hevner, 2013) on the concept development of a virtual and physical environment for prototyping industrial services. The development of CoProtolab concept followed the principles of axiomatic design (Suh, 2001). This research demonstrated the use of $\mathrm{AD}$ in developing a practical service prototyping environment. The customer domain described the needs of industrial companies for new service prototyping solutions based on a multidisciplinary literature. The needs guided the identification of the functional requirements (FRs). The analysis of the possibilities, challenges and solution frameworks related to NSD crystallised the requirements into effective, comprehensive, collaborative and immersive prototyping. The functional requirements guided the development of the physical domain, in which the design parameters (DPs) were solved through the templates of libraries for standard and customized, multisensory and temporal service elements. Finally, the process variables (PVs) described the use processes of the virtual and physical prototyping environment: initialisation and iterative development of a prototype as well as insuring and informing about a prototype.

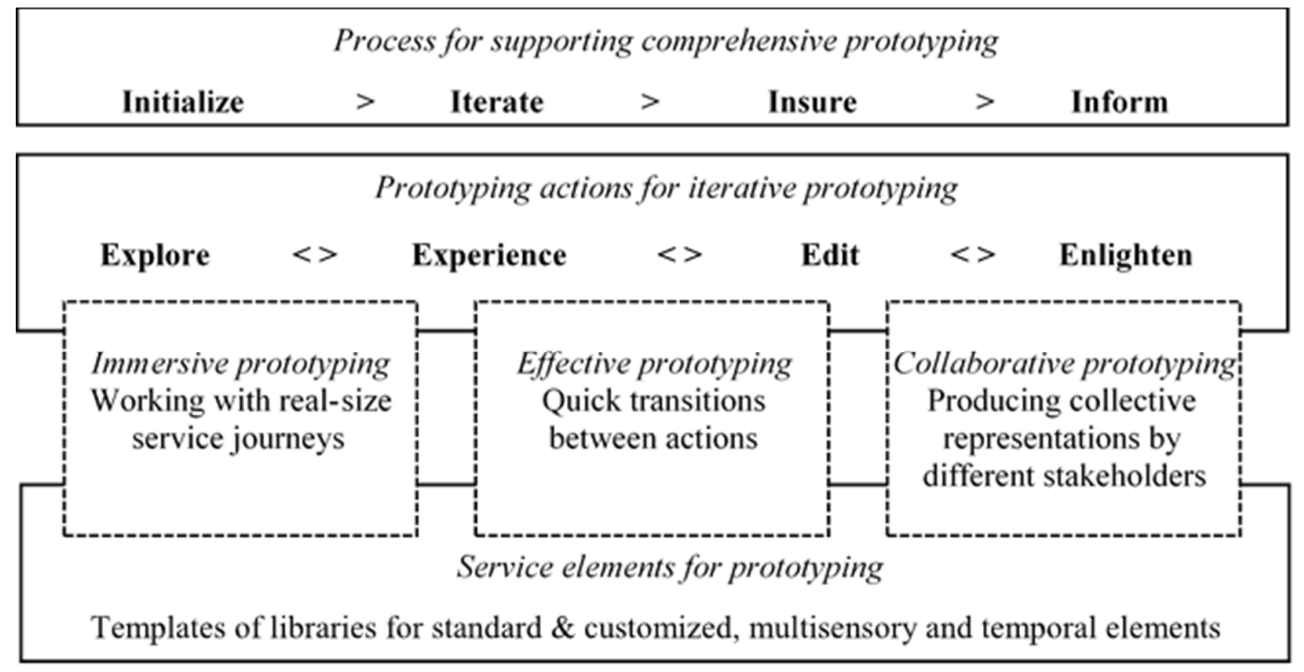

Figure 4. Rapid prototyping environment for industrial services

Figure 4 describes a theoretical model build upon the concept development. In service prototyping, the tangible, intangible and temporal elements of PSS (Morelli, 2002) translate into static or dynamic representations (Blomkvist, 2014) of service journeys. The representations enable exploration, evaluation and communication of future services (Blomkvist, 2014), which can be experienced (Miettinen et al., 2012) and edited simultaneously (Miettinen et al., 2012). 3D simulated user scenarios of service concepts (Clark et al., 2000) enable the exploration of complex system solutions in detail and timely manner (Hjelseth et al., 2015). When customers participate in describing their service journeys in VR (Hjelseth et al., 2015), the prototypes can cover the needed broader picture of value creation than service usage (see Heinonen et al., 2010).

This paper suggests that the presented CoProtolab concept enhances effective and immersive, collaborative and comprehensive prototyping of industrial services. The quick transitions between the prototyping actions can increase the effectiveness, while experiencing and exploring real-size service journeys simultaneously in VR can support immersive prototyping. Producing a collective representation of future services with different stakeholders enable collaborative prototyping. The concept can support comprehensive prototyping because it covers the early phases of NSD from initialisation of the service development, iterating with a prototype, to insuring service solutions and informing critical stakeholders.

Based on the study, service prototyping environment can help to overcome the challenges related to framing and scheduling NSD and cross-functional collaboration in NSD. (Kindström and Kowalkowski, 2009) Service prototyping sequences actions (Oh et al., 2013), explores actors and organizational 
structures through scenarios (Morelli, 2006), and enables exploration, visualization and testing of service concepts (Bae and Leem, 2014). Furthermore, prototyping can be used for answering to the need of a clear and flexible process for co-creating, designing and getting feedback on PSS solutions (Vasantha et al., 2012). In addition, combining intellectual property rights with prototyping process can benefit commercialization of a service prototype.

This study has also its limitations. The CoProtolab concept need to be implemented, tested and evaluated in order to verify the research findings. Nonetheless, researchers can use the results in discovering new research topics when studying industrial service prototyping and virtual, physical and social environments for supporting prototyping. Service developers can use the concept for guiding the structured development of industrial services through prototyping.

\section{References}

Arrasvuori, J., Kuusisto, A. and Kuusisto, J. (2015), "The Uses of IP Management Methods in Innovative SMEs", The 16th Annual International CINet Conference, Stockholm, Sweden, September 13-15, 2015.

Bae, D.J. and Leem, C.S. (2014), “A visual interactive method for service prototyping”, Managing Service Quality, Vol. 24 No. 4, pp. 339-362. https://doi.org/10.1108/MSQ-12-2013-0281

Baines, T., Lightfoot, H.W., Benedettini, O. and Kay, J.M. (2009), “The servitization of manufacturing”, Journal of Manufacturing Technology Management, Vol. 20 No. 5, pp. 547-567. https://doi.org/10.1108/IJOPM-022012-0086

Bitner, M.J. (1992), "Servicescapes: The Impact of Physical Surroundings on Customers and Employees", Journal of Marketing, Vol. 56 No. 2, p. 57. https://doi.org/10.2307/1252042

Bitner, M.J., Ostrom, A.L. and Morgan, F.N. (2008), "Service Blueprinting: A Practical Technique for Service Innovation", California Management Review, Vol. 50 No. 3, pp. 66-94. https://doi.org/10.2307/41166446

Blomkvist, J. (2014), Representing Future Situations of Service. Prototyping in Service Design, Lindköping University. https://doi.org/10.3384/diss.diva-105499

Bruno, F. and Muzzupappa, M. (2010), "Product interface design : A participatory approach based on virtual reality", Journal of Human Computer Studies, Vol. 68 No. 5, pp. 254-269. https://doi.org/10.1016/j.ijhcs.2009.12.004

Clark, G., Johnston, R. and Shulver, M. (2000), "Exploiting the service concept for service design and developmen", In: Fitzsimmons, J.A. and Fitzsimmons, M.J. (Eds.), New Service Development: Creating Memorable Experiences, Sage Publications, USA, pp. 71-91.

Coughlan, P., Suri, J.F. and Canales, K. (2007), "Prototypes as (Design) Tools for Behavioral and Organizational Change", The Journal of Applied Behavioral Science, Vol. 43 No. 1, pp. 122-134. https://doi.org/10.1177/0021886306297722

de Vasconcelos, A.M., Barichello, R., Lezana, Á., Forcellini, F.A., Ferreira, M.G.G. and Cauchick Miguel, P.A. (2015), "Conceptualisation of the service experience by means of a literature review", Benchmarking: An International Journal, Vol. 22 No. 7, pp. 1301-1314. https://doi.org/10.1108/BIJ-08-2013-0078

Edvardsson, B. and Olsson, J. (1996), "Key Concepts for New Service Development", The Service Industries Journal, Vol. 16 No. 2, pp. 140-164. https://doi.org/10.1080/02642069600000019

Flint, D.J. (2002), "Compressing new product success-to-success cycle time deep customer value understanding and idea generation", Industrial Marketing Management, Vol. 31 No. 4, pp. 305-315. https://doi.org/10.1016/S0019-8501(01)00165-1

Gebauer, H., Fleisch, E. and Friedli, T. (2005), "Overcoming the service paradox in manufacturing companies", European Management Journal, Vol. 23 No. 1, pp. 14-26, https://doi.org/10.1016/j.emj.2004.12.006

Goldstein, S.M., Johnston, R., Duffy, J. and Rao, J. (2002), "The service concept: The missing link in service design research?”, Journal of Operations Management, Vol. 20 No. 2, pp. 121-134. https://doi.org/10.1016/S0272-6963(01)00090-0

Gray, M., Mangyoku, M., Serra, A., Sánchez, L. and Aragall, F. (2014), "Integrating design for all in living labs", Technology Innovation Management Review, Vol. 4 No. 5, pp. 50-59.

Gregor, S. and Hevner, A.R. (2013), "Positioning and Presenting Design Science Research for Maximum Impact", MIS Quarterly, Vol. 37 No. 2, pp. 337-355. https://doi.org/10.2753/MIS0742-1222240302

Grönroos, C. (2008), "Service logic revisited: who creates value? And who co-creates?", European Business Review, Vol. 20 No. 4, pp. 298-314. https://doi.org/10.1108/09555340810886585

Gustafsson, A., Kristensson, P. and Witell, L. (2012), "Customer co-creation in service innovation: a matter of communication?", Journal of Service Management, Vol. 23 No. 3, pp. 311-327. https://doi.org/10.1108/09564231211248426 
Haase, R.P., Pigosso, D.C.A. and McAloone, T.C. (2017), "Product/Service-System Origins and Trajectories: A Systematic Literature Review of PSS Definitions and their Characteristics", Procedia CIRP, Vol. 64, pp. 157162. https://doi.org/10.1016/j.procir.2017.03.053

Heinonen, K. and Strandvik, T. (2015), "Customer-dominant logic: foundations and implications", Journal of Services Marketing, Vol. 29 No. 6/7, pp. 472-484. https://doi.org/10.1108/JSM-02-2015-0096

Heinonen, K., Strandvik, T., Mickelsson, K.-J., Edvardsson, B., Sundström, E. and Andersson, P. (2010), “A customer-dominant logic of service", Journal of Service Management, Vol. 21 No. 4, pp. 531-548. https://doi.org/10.1108/09564231011066088

Heinonen, K., Strandvik, T. and Voima, P. (2013), “Customer dominant value formation in service”, European Business Review, Vol. 25 No. 2, pp. 104-123. https://doi.org/10.1108/09555341311302639

Helo, P., Gunasekaran, A. and Rymaszewska, A. (2017), Designing and Managing Industrial Product-Service Systems, Springer, Cham. https://doi.org/10.1007/978-3-319-40430-1

Hjelseth, S., Morrison, A. and Nordby, K. (2015), "Design and Computer Simulated User Scenarios : Exploring Real-time 3D Game Engines and Simulation in the Maritime Sector", International Journal of Design, Vol. 9 No. 3, pp. 63-76.

Isaksson, O., Larsson, T. and Johansson, P. (2011), "Towards a Framework for Developing Product/service Systems", In: Hesselbach, J. and Herrmann, C. (Eds.), Functional Thinking for Value Creation, Springer, Berlin, Heidelberg, pp. 44-49. https://doi.org/10.1007/978-3-642-19689-8_10

Jégou, F. and Manzini, E. (2008), Collaborative Services - Social Innovation and Design for Sustainability, POLI.design.

Kimita, K., Shimomura, Y. and Arai, T. (2009), "Evaluation of customer satisfaction for PSS design”, Journal of Manufacturing Technology Management, Vol. 20 No. 5, pp. 654-673. https://doi.org/10.1108/17410380910961046

Kindström, D. and Kowalkowski, C. (2009), "Development of industrial service offerings: a process framework", Journal of Service Management, Vol. 20 No. 2, pp. 156-172. https://doi.org/10.1108/09564230910952753

Kuliga, S.F., Thrash, T., Dalton, R.C. and Hölscher, C. (2015), "Virtual reality as an empirical research tool Exploring user experience in a real building and a corresponding virtual model", Computers, Environment and Urban Systems, Vol. 54, pp. 363-375. https://doi.org/10.1016/j.compenvurbsys.2015.09.006

Lagrosen, S. (2005), "Customer involvement in new product development: A relationship marketing perspective", European Journal of Innovation Management, Vol. 8 No. 4, pp. 424-436. https://doi.org/10.1108/14601060510627803

Lammi, M. (2017), "Emotional service experience toolkit for servitization”, The Design Journal, Vol. 20, pp. S2667-S2678. https://doi.org/10.1080/14606925.2017.1352778

Mager, B. (2009), "Service design - an emerging field", In: Satu, M. and Koivisto, M. (Eds.), Designing Services with Innovative Methods, Otava Book Printing Ltd, Keruu.

McCurdy, M., Connors, C., Pyrzak, G., Kanefsky, B. and Vera, A. (2006), "Breaking the Fidelity Barrier - An Examination of our Current Characterization of Prototypes and an Example of a Mixed-Fidelity Success", Proceedings of the International Conference on Human Factors in Computing Systems (CHI'06), pp. 12331242. https://doi.org/10.1145/1124772.1124959

Meiren, T. and Burger, T. (2010), "Testing of service concepts”, The Service Industries Journal, Vol. 30 No. 4 , pp. 621-632. https://doi.org/10.1080/02642060903144321

Miettinen, S. (2017), An Introduction to Industrial Service Design, Routledge, Oxon.

Miettinen, S. and Kuure, E. (2013), "Designing a Multi-Channel Service Experience", Design Management Review, Vol. 24 No. 3, pp. 30-37. https://doi.org/10.1111/drev.10248

Miettinen, S., Rontti, S., Kuure, E. and Lindström, A. (2012), "Realizing Design Thinking through a Service Design Process and an Innovative Prototyping Laboratory-Introducing Service Innovation Corner (SINCO)", DRS 2012, Bangkok, Thailand, July 1-4, 2012.

Morelli, N. (2002), "Designing Product / Service Systems: A Methodological Exploration”, Design Issues, Vol. 18 No. 3, pp. 3-17. https://doi.org/10.1162/074793602320223253

Morelli, N. (2006), "Developing new product service systems (PSS): methodologies and operational tools", Journal of Cleaner Production, Vol. 14 No. 17, pp. 1495-1501. https://doi.org/10.1016/j.jclepro.2006.01.023

Morelli, N. (2007), "Social Innovation and New Industrial Contexts: Can Designers 'Industrialize' Socially Responsible Solutions?”, Design Issues, Vol. 23 No. 4, pp. 3-21. https://doi.org/10.1162/desi.2007.23.4.3

Nguyen, H.N., Exner, K., Schnürmacher, C. and Stark, R. (2014), "Operationalizing IPS2 development process: A method for realizing IPS2 developments based on Process-based project planning", Procedia CIRP, Vol. 16, pp. 217-222. https://doi.org/10.1016/j.procir.2014.01.024

Nguyen, H.N., Müller, P. and Stark, R. (2013), "Transformation towards an IPSS business: A deployment approach for process-based PSS development projects", Proceedings of 4th CIRP International Conference on Industrial Product-Service Systems, pp. 251-252. 
Oh, K., Lee, J.S., Kim, S.-K., Jung, J.-Y. and Kim, B. (2013), "Service Prototyping for Service Testing in Virtual Reality”, International Journal of Information and Electronics Engineering, Vol. 3 No. 3, pp. 304-308. https://doi.org/10.7763/IJIEE.2013.V3.323

Ostrom, A.L., Parasuraman, A., Bowen, D.E., Patrício, L. and Voss, C.A. (2015), "Service Research Priorities in a Rapidly Changing Context”, Journal of Service Research, Vol. 18 No. 2, pp. 127-159. https://doi.org/10.1177/1094670515576315

Parker, S. and Heapy, J. (2006), The Journey to the Interface: How Public Service Design Can Connect Users to Reform, Demos, London.

Prahalad, C.K. and Ramaswamy, V. (2000), “Co-opting Customer Competence”, Harvard Business Review, Vol. 78 No. 1 , pp. $79-87$.

Pruitt, J. and Adlin, T. (2010), The Persona Lifecycle: Keeping People in Mind Throughout Product Design, Morgan Kaufmann, Oxford.

Rodrigues, V.P., Pigosso, D.C.A. and McAloone, T.C. (2017), "Simulation-Based Business Case for PSS: A System Dynamics Framework", Procedia CIRP, Vol. 64, pp. 283-288. https://doi.org/10.1016/j.procir.2017.03.014

Segelström, F. (2013), Stakeholder Engagement for Service Design, Lindköping University.

Shostack, G.L. (1982), "How to Design a Service", European Journal of Marketing, Vol. 6 No. 1, pp. $49-63$. https://doi.org/10.1108/JHOM-09-2016-0165

Stickdorn, M., Sneider, J., Bisset, F., Kelly, L., Raijimakers, B. and VanDijk, G. (2010), This Is Service Design Thinking, BIS Publishing, Amsterdam.

Suh, N.P. (1998), “Axiomatic Design Theory for Systems”, Research in Engineering Design, Vol. 10 No. 4 , pp. 189-209. https://doi.org/10.1007/s001639870001

Suh, N.P. (2001), Axiomatic Design: Advances and Applications. Oxford Series on Advanced Manufacturing, Oxford University Press.

Thackara, J. (2005), In the Bubble: Designing in a Complex World, Azure Publishing Inc., Toronto, Canada.

Vaajakallio, K. and Mattelmäki, T. (2014), "Design games in codesign: as a tool, a mindset and a structure", CoDesign, Vol. 10 No. 1, pp. 63-77. https://doi.org/10.1080/15710882.2014.881886

Vargo, S.L. and Lusch, R.F. (2011), "It's all B2B...and beyond: Toward a systems perspective of the market", Industrial Marketing Management, Vol. $40 \quad$ No. $\quad 2, \quad$ pp. $181-187$. https://doi.org/10.1016/j.indmarman.2010.06.026

Vasantha, G.V.A., Roy, R., Lelah, A. and Brissaud, D. (2012), "A review of product-service systems design methodologies", Journal of Engineering Design, Vol. 23 No. 9, pp. 635-659. https://doi.org/10.1080/09544828.2011.639712

Voima, P., Heinonen, K. and Strandvik, T. (2010), Exploring Customer Value Formation - a Customer Dominant Logic Perspective. [online] Publications of Hanken School of Economics. Available at: https://helda.helsinki.fi/dhanken/handle/10227/630

Wallin, T., Kristensson, A.P., Lervik-Olsen, L., Parasuraman, A., Mccoll-Kennedy, J.R. et al. (2016), "Linking service design to value creation and service research", Journal of Service Managemen, Vol. 27 No. 1, pp. 2129. https://doi.org/10.1108/JOSM-04-2015-0123

Wetter-Edman, K., Sangiorgi, D., Edvardsson, B., Holmlid, S., Grönroos, C. and Mattelmäki, T. (2014), "Design for Value Co-Creation: Exploring Synergies Between Design for Service and Service Logic", Service Science, Vol. 6 No. 2, pp. 106-121. https://doi.org/10.1287/serv.2014.0068

Miia Elina Lammi, Development manager

VAMK Ltd, University of Applied Sciences, Design Centre MUOVA

Wolffintie 36 F 11, 65200 Vaasa, Finland

Email: miia.lammi@muova.fi 